\title{
Food intake following blood mixing of hungry and satiated rats
}

JOHN D. DAVIS ${ }^{1}$

UNIVERSITY OF ILLINOIS AT CHICAGO CIRCLE

\begin{abstract}
The milk intake of food deprived and satiated rats was measured following the complete mixing of their blood by a new technique. It was found that this procedure neither decreased the subsequent intake of the deprived animals nor increased the intake of satiated animals. Problem
\end{abstract}

How does a rat regulate its intake when it has access to food for only $1 \mathrm{hr}$. out of every 24 ? The fact that it eats rapidly for about $20 \mathrm{~min}$. when given food on this schedule, but stops before an appreciable amount of the ingested food can have been digested and absorbed suggests that perhaps chemicals released into the blood stream during ingestion act on neural structures to terminate eating.

The results of Luckhardt \& Carlson (1915) showing that, under certain conditions, the blood from a hungry dog transfused into a satiated one produces gastric motility in the latter, and the studies discussed by Bash (1939) showing that the blood from a satiated dog inhibited gastric motility in a hungry dog have frequently been cited in support of the existence of hunger and satiety hormones. Nevertheless, care must be taken in extrapolating from hunger measured by gastric motility to hunger measured by food intake. Changes in blood glucose levels can affect gastric activity without affecting food intake (see Soulairac, 1958).

Recently Hervey (1959) has shown that an unlesioned rat joined chronically in parabiosis with a hypothalamic hyperphagic mate became, in time, very thin in comparison with its partner, suggesting that impaired neural centers in the operated animal permitted an accumulation of a "satiety factor" in both partners cutting off the intake of the normal animal.But whether this interpretation is correct, or a blood factor was involved is still uncertain.

Since the parabiotic preparation seems to be a direct approach to the problem of finding a satiety or hunger hormone, but since chronic parabiosis does not permit quantitative evaluation of the role of a possible transcirculated chemical mediator, a method was developed for acutely transfusing the blood between a pair of unanesthetized rats.

\section{Method}

Male Sprague-Dawley rats 90 to 120 days old were first adapted to a $24 \mathrm{hr}$. feeding schedule permitting two $1 / 2 \mathrm{hr}$. periods of access to diluted condensed milk ( 3 parts milk to 1 part water). These drinking periods were separated by a $1 / 2 \mathrm{hr}$. period in which only water was available. Except during the milk drinking periods the animals had free access to water. This schedule was maintained for at least 10 days, by which time the milk intake had become asymptotic.

Following adaptation to this schedule, chronic intravenous cannulas similar to, but slightly larger than, those described by Weeks \& Davis (1964) were implanted. They entered the right external jugular vein and terminated either in the heart or just short of it in the superior vena cava. Transfusions were begun on the day following surgery.

\section{Transfusion Procedure}

Immediately prior to transfusion both rats were given (i.v.) $0.15 \mathrm{ml}$ Heparin (1000 units per $\mathrm{ml}$ ). The blood of the two rats was then mixed by successively withdrawing and reinjecting $2 \mathrm{ml}$ of blood at a time with two plastic syringes connected to the animals' cannulas with silicone rubber tubes. After each $2 \mathrm{ml}$ withdrawal the blood taken from each animal was reinjected into its mate. At least $20 \mathrm{ml}$ of blood, $2 \mathrm{ml}$ at a time, was transfused on the basis of the findings by Brodish \& Long (1954) that for 200-300 Sprague-Dawley rats the cross circulation of this amount of blood effects virtually complete mixing. The transfusions always occurred immediately after one member of the pair had had access to the diluted milk for $20 \mathrm{~min}$., enough time to satiate the animal. The deprived member of the pair had been without food for $22-1 / 2 \mathrm{hr}$. prior to the transfusion. Immediately following the transfusion, which required about $1 / 2 \mathrm{hr}$., both animals were re turned to their home cages where they had $1 / 2 \mathrm{hr}$. access to the diluted milk.

\section{Results and Diseussion}

Ten pairs of animals were run. Their mean intake on the last five test days before the first transfusion was $13.7 \mathrm{ml}$ in the first $1 / 2 \mathrm{hr}$. and $3.2 \mathrm{ml}$ in the second $1 / 2 \mathrm{hr}$. Following transfusion the mean intake of the deprived rats whose blood had been mixed with the blood of satiated rats was $13.8 \mathrm{ml}$ and the mean intake of the satiated rats whose blood had been mixed with the blood of deprived rats was $2.1 \mathrm{ml}$. The difference of $0.1 \mathrm{ml}$ between the intake of the deprived rats when on the adaptation schedule and the intake of the same rats immediately after their blood had been mixed with the blood of satiated rats is not statistically significant by the Walsh test. The mean difference of $1.1 \mathrm{ml}$ between the intake of the rats on the second $1 / 2$ hr. test and their intake following satiation and blood mixing with the blood of deprived rats approaches significance, but the null hypothesis cannot be rejected at the $5 \%$ level. 
These data offer no evidence that the approximately complete mixing of the blood of a satiated and a deprived rat leads either to a decrease in the intake of the deprived rat or an increase in the intake of the satiated rat. These results are consistent with the findings of Alekseeva (1958) who showed that feeding one of a pair of hungry Siamese twins did notallay the restlessness and crying apparently due to hunger in the other. They are also consistent with those of Adair (1965) who has shown that transfusing the blood of hungry and satiated rats does not appear to affect their rate of bar pressing on a VI reinforcement schedule.

Negative findings however, are difficult to interpret. Perhaps $50 \%$ mixing does not put enough of a satiety or hunger factor in either animal to have an effect. This possibility is currently being investigated by transfusing the blood of one hungry rat successively with the blood of two newly satiated rats to increase the concentration of any satiety factor which might normally inhibit ingestion. Another possible explanation of negative results is that a satiety factor does exist in the blood, but is deactivated in some way when circulated in a hungry animal. The method described here would not be adequate for the identification of this sort of process.

It is also recognized that, because this is a new method, it should be evaluated in a situation in which blood factors are known to play a role in the control of behavior. As a first step in this evaluation the author is transfusing the blood of thirsty and nonthirsty rats to determine the effect on water intake.

\section{References}

Adair, Eleanor R. Personal communication.

Alekseeva, T. T. Nervous and humeral factors in the maintenance of alimentary excitability in conjoined twins. Fiziol. zh. SSSR, 1958,44 , No, 4, 259-304.

Bash, K. W. Contributions to a theory of the hunger drive. J. comp. Psychol., 1939, 28, 137-160.

Brodish, A., \& Long, C. H. H. A technique of cross-circulation in the rat which permits accurate control of blood volume transfers. Yale J. Biol. Med., 1956, 28, 644-649.

Hervey, G. R. The effect of lesions in the hypothalamus in parabiotic rats. J. Physiol., 1959, 145, 336-352.

Luckhardt, A. B., \& Carlson, A. J. Contributions to the physiology of the stomach. XVII. On the chemical control of the gastric hunger mechanism. Amer. J. Physiol., 1915, 36, 37-46.

Soulairac, A. Les regulations psycho-physiologiques de la faim. J. Physiol. (Paris), 1958, 50, 663-783.

Weeks, J. R., \& Davis, J. D. Chronic intravenous cannulas for rats. J. appl. Physiol., 1964, 19, 540-541.

\section{Notes}

1. The cannulation technique and transfusion method were developed by the author under the support of NIMH grant 2949 to Neal E. Miller, who contributed to their development with many constructive suggestions. The author is also indebted to I. E. Farber for helpful comments on the problem and reading of the manuscript, and to Robert Gallagher and Robert Ladove for their extremely capable technical assistance. 